\title{
Magnesium pemoline: Effects on spontaneous activity, stimulus responsivity and food intake
}

\author{
J. GIANUTSOS, ${ }^{1}$ ROSAMOND GIANUTSOS, ${ }^{2}$ AND YASUKO \\ FILBY, CREEDMOOR INSTITUTE FOR PSYCHOBIOLOGIC \\ STUDIES, Station 60, Queens Village, N. Y. 11427
}

The mechanism by which magnesium pemoline ( $\mathrm{MgPe}$ ) facilitates active avoidance is unclear. Some hypothesize that the drug affects performance but not learning factors. In order to clarify the effects of $\mathrm{MgPe}$, this study investigated its effects on such simple behavior as spontaneous activity, food intake, and stimulus responsivity in rats over a 22-h period. $\mathrm{MgPe}$ significantly increased spontaneous activity but did not affect food intake and stimulus responsivity.

Magnesium pemoline, ${ }^{3}$ a mild CNS-stimulant, has been reported to enhance active avoidance (Plotnikoff, 1966; Beach \& Kimble, 1967; Filby, Szara, \& Salzman, 1967). However, the mechanism by which avoidance is enhanced is disputed. Several workers have suggested that $\mathrm{MgPe}$ affects performance (by increasing spontaneous activity and stimulus responsivity and/or decreasing freezing behavior) rather than learning (central associative) factors. Plotnikoff, however, has suggested that $\mathrm{MgPe}$ enhances learning by facilitating synaptic transmission.

In view of the conflicting interpretations of the effects of $\mathrm{MgPe}$, it was felt that more information regarding the behavioral effects of $\mathrm{MgPe}$ should be obtained in simple and varied situations. The present two studies investigated the dose-response relationship over a 22-h period between $\mathrm{MgPe}$ and three dependent variables: in Experiment 1, spontaneous activity and food intake, and in Experiment 2, stimulus responsivity.

\section{EXPERIMENT 1}

Subjects. Thirty naive male Osborn-Mendel rats, 120 days old at the start of the experiment, were randomly assigned to six groups: $5,10,20$, and $40 \mathrm{mg} / \mathrm{kg} \mathrm{MgPe}$, control-injection (.3\% tragacanth solution, the suspension used for the $\mathrm{MgPe}$ ) and no-injection groups.

Apparatus. Each $\mathbf{S}$ was tested in his home cage, which was suspended by a universal joint in one of five sound-insulated cubicles. The joint allowed the cage to move with any slight movement of the S. A prong, attached to one cage wall, extended horizontally out of the cage and made contact with a metal slot. Any movement of the cage resulted in a contact between the prong and the slot, which closed a circuit, activating recording devices in an adjacent sound-insulated room. This apparatus has been described in detail elsewhere (Gianutsos, 1968). White noise of $65 \mathrm{~dB}$ was present throughout all sessions. Temperature was kept constant at $70 \mathrm{deg} F$.

Procedure. The Ss were given IP injections of their drug immediately prior to being placed in the apparatus. Each $S$ was run six times, each session spaced a week apart, and lasting $22 \mathrm{~h}$. For the first three sessions, a $7 \frac{1}{2} \mathrm{~W}$ cubicle light was on during the first $11 \mathrm{~h}$, and off the second 11 . During the last three sessions, this was reversed. Each $S$ was run in the same cubicle over the six sessions. Groups were equally distributed among the five cubicles. Food and water were available in the cage at all times.

Results

Figure 1 shows that the higher the dose, the higher the activity level. Elevation in activity level was apparent immediately within the $1 \mathrm{st} \mathrm{h}$, and tapered off by the 14th $\mathrm{h}$ or so. An analysis of variance yielded a significant interaction of Drug Treatment by Hours (as well as significant main effects due to hours, and to drugs). There was also a sma!i but significant difference due to sessions; however, the session means showed no systematic trend, indicating that no habituation to the drug occurred. This small but significant sessions effect appeared to be due to the unreliability of the method of injection (which was IP) since the control group showed very little variation over sessions. Similarly, significant interactions of Sessions by Hours, and Drugs by Sessions were probably also due to this variable.
An analysis of variance on food intake showed no significant difference between drug groups, indicating that the drug had no anorexic effect when given a week apart.

\section{EXPERIMENT 2}

Subjects. Another group of 30 naive male Osborn-Mendel rats, 120 days old at the start of the experiment, were randomly assigned to the same six groups: $5,10,20$, and $40 \mathrm{mg} / \mathrm{kg} \mathrm{MgPe}$, control-injection (.3\% tragacanth) and no-injection groups.

Apparatus. This was identical to Experiment 1.

Procedure. The Ss were injected IP immediately prior to being run. Each $S$ was run once, in a single 22-h session. The cubicle light was on during the first $11 \mathrm{~h}$, and off during the second 11 . Groups were distributed equally among the five cubicles. Food and water were available in the cages. Once every hour, periodically, a buzzer of $1000 \mathrm{cps} 70 \mathrm{~dB}$ sounded for $30 \mathrm{sec}$. Activity level during the $30 \mathrm{sec}$ of buzzer, and during the 30 secs immediately preceding and following the buzzer, were recorded in an adjacent sound-insulated room.

\section{Results}

An analysis of variance on activity scores showed that activity was significantly heightened during and following the $30 \mathrm{sec}$ buzzer (the overall means being 9.6, 11.6, and 11.2 for the $30 \mathrm{sec}$ before, during, and after buzzer). Again, there was a significant Drug Treatment by Hours interaction (as in Experiment 1). There was a significant effect over Hours, but main drug treatment effects fell just short of significance.

\section{DISCUSSION}

Experiment 1 showed that activity level was increased with increasing doses of $\mathrm{MgPe}$. The increased activity due to $\mathrm{MgPe}$ occurred within the first $h$ and lasted approximately $14 \mathrm{~h}$ (Fig. 1). By the last five to six $h$, activity returned to the no-injection group level. In Experiment 2, activity level was increased by the sounding of a loud buzzer, but this buzzer effect was not significantly enhanced by MgPe at any dose. This is probably due to a ceiling effect of the buzzer which caused maximal hyperactivity in the Ss. We did not obtain a significant interaction of Buzzer Effects by Drug Treatments by Hours, indicating that the groups did not adapt differentially to the buzzer over the $22 \mathrm{~h}$. That is, $\mathrm{MgPe}$ did not increase or maintain stimulus responsivity in a situation where the buzzer occurs without any contingencies-i.e., did not signal an impending change in the environment, such as shock. ${ }^{4}$ This is in contrast to the conclusions of Beach \& Kimble (1967) that $\mathrm{MgPe}$ Ss maintain responsivity whereas controls show habituation. However, a visual examination of their data suggest that if baseline activity (pre-buzzer activity level) is taken into consideration, the controls show as much initial responsivity to the buzzer onset as MgPe animals.

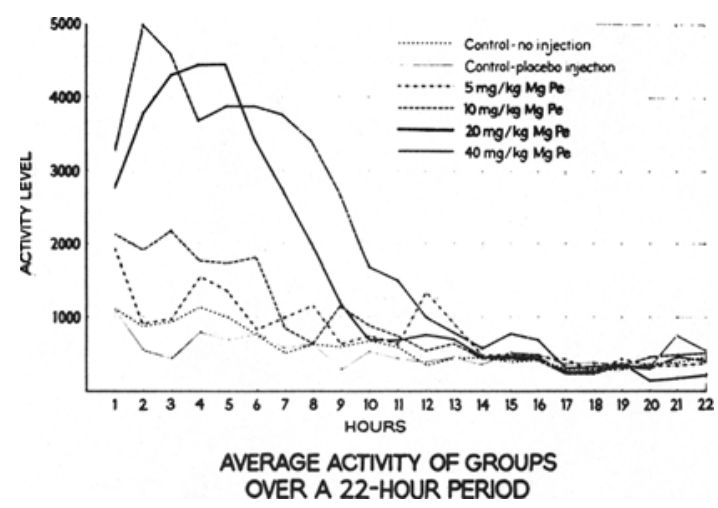

Fig. 1. Activity levels over $22 \mathrm{~h}$ of $\mathrm{MgPe}$ and control groups. 
However, by the 17th $\mathrm{h}$ or so in our Experiment 2 (when drug effects wear off according to results of Experiment 1) there was a noticeable tendency for the higher dose $(10-, 20$, and $40-\mathrm{mg} / \mathrm{kg})$ rats to depress activity, a phenomenon similar to that observed by Boitano \& Boitano (1967) who hypothesized a "rebound" effect due to a "central homeostatic inhibitory mechanism which limited overt activity after a period of prolonged hyperexcitability."

The present study adds confirmation to the suggestions of other workers (e.g., Filby \& Frank, 1968) that the enhanced performance of $\mathrm{MgPe}$ animals in active avoidance situations (Plotnikoff, 1966) is due to a drug-induced increase in spontaneous motor behavior, rather than due to a drug-induced improvement in central associative factors. Recently, in order to obviate this criticism, Plotnikoff (1967) gave post-learning administrations of $\mathrm{MgPe}$ and obtained enhanced retention of avoidance performance one and two weeks later. In a separate study (unpublished study), however, we failed to obtain memory consolidation with $\mathrm{MgPe}$ when rats were injected with 1.5, 5, 10, or $20 \mathrm{mg} / \mathrm{kg} \mathrm{MgPe}$ following simple learning and tested a day, a week, or a month later.

\section{REFERENCES}

BEACH, G., \& KIMBLE, D. P. Activity and responsitivity in rats after magnesium pemoline injections. Science, 1967, 155, 698-701.

BOITANO, J. J., \& BOITANO, JOAN C. Magnesium pemoline: Enhancement of spontaneous motor activity. Psychon. Sci, 1967, 9, 295-296.

FILBY, YASUKO, \& FRANK, LUCILLE. Magnesium pemoline: Effects on drl performance. Psychon Sci, 1968, 10, 265-266.

FILBY, YASUKO, SZARA, S., \& SALZMAN, B. Magnesium pemoline: Effect on acquisition and retention of discriminated avoidance behavior. Psychon. Sci, 1967, 9, 131-132.

GIANUTSOS, J. An inexpensive method of measuring spontaneous activity. Manuscript in preparation.

PLOTNIKOFF, N. Magnesium pemoline: enhancement of learning and memory of a conditioned avoidance response. Science, 1966, 157, 703-704.

PLOTNIKOFF, N. Pemoline and magnesium hydroxide: Memory consolidation following acquisition trials. Psychon Sci, 1967, 9, 141-142.

\section{NOTES}

1. Now at Adelphi University, Garden City, New York.

2. At New York University, New York, N.Y.

3. We thank Abbott Laboratories for supplying the magnesium pemoline.

4. In situations where buzzer does signal impending shock, however, as in discriminated avoidance situations, MgPe animals show superior learning than d-amphetamine controls (Filby, Szara, \& Salzman, 1967). 